\title{
Cardiac performance evaluation in children with nephrotic syndrome
}

\author{
Ashraf S. Kamel ${ }^{(1)}$, Sara I. Abo Elnour ${ }^{(2)}$, Marwa M. Ragaey Mahmoud ${ }^{(3)}$ \\ (1) Assistant Professor of Pediatrics, Faculty of Medicine, Fayoum University. \\ (2) Lecturer of Pediatrics, Faculty of Medicine, Fayoum University. \\ (3) Pediatrics department, Faculty of Medicine, Fayoum University.
}

Corresponding author: Dr. Ashraf Sayed Kamel

E-mail: ashraf5kam@yahoo.com.

Tel: 01225876153

\begin{abstract}
Background: Primary Nephrotic syndrome (PNS) is one of the most important kidney diseases in paediatric age group. Cardiac affection in patients with nephrotic syndrome may be attributable to the malnutrition and activated inflammatory state accompanying the sustained proteinuria. Tissue Doppler imaging is a useful echocardiographic technique to evaluate global and regional myocardial systolic as well as diastolic function. The myocardial performance index (MPI), also known as the Tei index is more sensitive than classic echocardiographic parameters, particularly in showing subclinical myocardial function compromise and calculated by dividing the sum of isovolumetric relaxation time (IVRT) and isovolumetric contraction time (IVCT) by ejection time (ET).
\end{abstract}

Aim of work: To assess cardiac performance in children with primary nephrotic syndrome using conventional echocardiography and tissue Doppler imaging.

Subjects and methods: This study was conducted in outpatient Nephrology Clinic jointly with Cardiology Unit of Pediatric Department at Fayoum University Hospitals. It included 30 patients with primary nephrotic syndrome and 30 age and sex matched healthy subjects as a control group. Doppler echocardiography was performed using a Vivid 5 color Doppler ultrasound system General
Electric with transducers of $3.75 \mathrm{MHz}$ or 5 MHz.

Results: The difference between patient group and control group in conventional echocardiography was not significant with the exception of LVESD which was significantly higher in patient group compared to control group $(\mathrm{p}=0.034)$. As regards tissue echocardiography, there was significant difference between patient and control groups as regards IVCT ( $p<0.0001)$ and mean MPI of the right ventricle ( $p$ value $=0.006)$, there was significant differences between patient and control groups as regards IVRT $(\mathrm{p}=0.005)$, $\operatorname{IVCT}(\mathrm{p}=0.032), \mathrm{E}(\mathrm{p}=0.003), \mathrm{A}(\mathrm{p}=0.003)$ and mean MPI of the left ventricle $(\mathrm{p}=0.009)$. Right ventricle MPI was increased in $30 \%$ of children with PNS while left ventricle MPI was increased in $20 \%$.

Conclusion: Right ventricle functions were affected in $30 \%$ of children with PNS and left ventricle functions were affected in $20 \%$ of cases. Right and left ventricle dysfunctions were significantly correlated with disease duration, treatment duration, relapse, steroid resistance and with immune- suppressive drugs.

Keywords: Primary nephrotic syndrome, myocardial performance index.

\section{Introduction}

Childhood nephrotic syndrome is one of the most common of pediatric kidney diseases, which has an incidence of 2-7 per 100000 
children. ${ }^{(1)}$ It is characterized by a triad of proteinuria, edema, and hypoalbuminemia. ${ }^{\text {(2) }}$ Primary nephritic syndrome (PNS) is the most common type in children. ${ }^{(3)}$

Protein wasting and systemic inflammatory activation during PNS may contribute to cardiac remodeling and dysfunction. ${ }^{(4)}$ Acute afterload elevations would result in decreased relaxation rate and increased diastolic intolerance to afterload in children with PNS. ${ }^{(5)}$

PNS is also associated with hypercoagulability and an increased tendency for thromboembolism. ${ }^{(6)}$ These children also get exposed to other risk factors associated with impaired endothelial function and adverse cardiovascular outcomes like high oxidative stress, frequent infections, sustained proteinuria, hypoalbuminemia, thromboembolism, toxicity of steroids and non-steroidal drugs like calcineurin inhibitors that cause hyperlipidemia,vasculotoxic and nephrotoxic effects. ${ }^{(7)}$

The aim of this work was to assess cardiac performance in children with primary nephrotic syndrome using conventional echocardiography and tissue Doppler imaging.

\section{Subjects and methods}

This study included 30 children diagnosed with primary nephrotic syndrome at the nephrology outpatient clinic of Pediatric Department, Fayoum University Hospitals and 30 age and sex matched healthy subjects as a control group.

\section{Inclusion criteria:}

- Children with primary nephritic syndrome.

- Age: 2 - 14 year.

- Both males and females.

\section{Exclusion criteria:}

- Patients with known congenital or acquired heart disease.

Full history taking and clinical examination were done for all subjects.
Laboratory investigations included $\mathrm{CBC}$, serum albumin, urea, creatinine, urine analysis, albumin creatinine ratio $\mathrm{AlC}$ and serum cholesterol.

Echocardiography was performed using a Vivid 5 color Doppler ultrasound system General Electric with transducers of $3.75 \mathrm{MHz}$ or $5 \mathrm{MHz}$, as appropriate for children or adolescents.

A complete echocardiographic examination was performed to exclude the possibility of congenital heart disease with great emphasis on RV dimensions, Global function, LV internal dimensions with assessment of LV ejection fraction.

From the standard transthoracic windows, LV end diastolic diameter (LVEDD), LV end systolic diameter (LVESD), LV posterior wall (LVPW), and LV ejection fraction (EF) were measured.

Transmitral E wave velocity (E) and (A) wave velocity were averaged to generate the mean value.

MPI was calculated by dividing the sum of IVRT and IVCT by Ejection time (ET). RV MPI $=($ IVCT + IVRT $) /$ RVET. LV MPI = (IVCT + IVRT) / LVET

Right ventricular and left ventricular functions were evaluated by MPI, increased MPI indicate the presence of diastolic dysfunction.

\section{Statistical methods:}

The collected data was organized, tabulated and statistically analyzed using SPSS software statistical computer package version 22 (SPSS Inc, USA). For quantitative data, the mean and standard deviation were calculated. Comparison between any two groups as regards study variables was done using Independent t-test. Qualitative data was described as frequencies (number) and percentages; chi- square test was used as a test of significance. For interpretation of results of tests of significance, significance was adopted at $\mathrm{p} \leq 0.05$.

\section{Ethical consideration:}


The study was approved by the Faculty of Medicine Research Ethical Committee.
Informed written consent was obtained from all study participants legal guardians.

\section{Results}

The demographic characteristics of the study groups are summarized in Table 1 . The mean age was $6.5 \pm 3.3$ years for the PNS patient group and $7.3 \pm 2.4$ years for the control group. The PNS patient group included 19 males and 11 females and the control group included 13 males and 17 females.

Echocardiography characteristics in both study groups are shown in table 2. Left ventricular end systolic diameter (LVESD) was significantly higher in patient group compared to control group $(\mathrm{p}=0.034)$.

Comparison between patient group and control group as regards tissue Doppler of the right ventricle is shown in table 3. There was significant difference between patient and control groups as regards IVCT $(\mathrm{p}<0.0001)$ and mean MPI of the right ventricle ( $\mathrm{p}$ value $=0.006$ ).

Comparison between patient group and control group as regards tissue Doppler of the left ventricle is shown in table 4 . There was significant differences between patient and control groups as regards IVRT $(p=0.005), \operatorname{IVCT}(p=0.032), E(p=0.003), A(p=0.003)$ and mean MPI of the left ventricle $(\mathrm{p}=0.009)$.

As regards right ventricle MPI, 9/30 (30\%) of the patient group showed high MPI while 21/30 (70\%) showed normal MPI. Comparison between patients with high and normal MPI RV as regards disease characteristics is shown in table 5 and figures $1,2,3$. High MPI RV was associated with disease duration $(\mathrm{p}=0.007)$, treatment duration $(\mathrm{p}=0.034)$, relapse $(\mathrm{p}<0.0001)$, steroid resistance $(\mathrm{p}=0.025)$ and immune- suppressive treatment $(\mathrm{p}=$ $0.025)$.

As regards left ventricle MPI, 6/30 (20\%) of the patient group showed high MPI while 24/30 (80\%) showed normal MPI. Comparison between patients with high and normal MPI LV as regards disease characteristics is shown in table 6 and figures 4, 5, 6. High MPI LV was associated with disease duration $(p=0.031)$, treatment duration $(p=0.026)$, relapse $(\mathrm{p}<0.0001)$, steroid resistance $(\mathrm{p}=0.003)$ and immune- suppressive treatment $(\mathrm{p}=$ $0.003)$.

Table (1): Demographic characteristics of different study groups.

\begin{tabular}{|c|c|c|c||}
\hline Variables & $\begin{array}{c}\text { PNS patients } \\
(\mathbf{n = 3 0})\end{array}$ & $\begin{array}{c}\text { Controls } \\
(\mathbf{n = 2 0 0})\end{array}$ & p-value \\
\hline Age (years) & $6.5 \pm 3.3$ & $7.3 \pm 2.4$ & 0.334 \\
\hline Mean \pm SD & $19(63.3 \%)$ & $18(60 \%)$ & \multirow{2}{*}{0.121} \\
\hline Gender & $11(36.7 \%)$ & $97(40 \%)$ & \\
\hline Male (\%) & \multicolumn{3}{|c|}{9} \\
\hline
\end{tabular}


Table (2): Echocardiography characteristics in both study groups

\begin{tabular}{|l|c|c|c|c|c||}
\hline \multirow{2}{*}{ Variable } & \multicolumn{2}{|c|}{$\begin{array}{c}\text { PNS patients } \\
(\mathbf{n = 3 0 )}\end{array}$} & \multicolumn{2}{c|}{$\begin{array}{c}\text { Controls } \\
(\mathbf{n = 3 0})\end{array}$} & \multirow{2}{*}{ p-value } \\
\cline { 2 - 5 } & Mean & SD & Mean & SD & \\
\hline PAP & 19.6 & 4.8 & 17.9 & 2.1 & 0.089 \\
\hline LAD & 2.3 & 0.2 & 2.2 & 0.2 & 0.238 \\
\hline LVEDD & 3.7 & 0.5 & 3.9 & 0.3 & 0.100 \\
\hline LVESD & 2.5 & 0.3 & 2.3 & 0.3 & $\mathbf{0 . 0 3 4}$ \\
\hline LVPWD & 0.6 & 0.2 & 0.6 & 0.1 & 0.934 \\
\hline EF & 36.9 & 3.6 & 37.4 & 2.5 & 0.510 \\
\hline FS & 67.2 & 4.5 & 67.7 & 2.7 & 0.579 \\
\hline RVD & 1.3 & 0.1 & 1.3 & 0.1 & 0.061 \\
\hline
\end{tabular}

PAP: pulmonary artery pressure; LAD: left atrial diameter; LVEDD: left ventricular end diastolic diameter; LVESD: left ventricular end systolic diameter; LVPWD: Left ventricular posterior wall diameter; EF: ejection fraction; FS: fraction shortening; RVD: right ventricle dimension.

Table (3): Comparison between patients and controls as regards tissue Doppler of the right ventricle

\begin{tabular}{|c|c|c|c|c|c|}
\hline \multirow[t]{2}{*}{ Variable } & \multicolumn{2}{|c|}{$\begin{array}{c}\text { PNS patients } \\
(n=30)\end{array}$} & \multicolumn{2}{|c|}{$\begin{array}{c}\text { Controls } \\
(\mathbf{n}=\mathbf{3 0})\end{array}$} & \multirow[t]{2}{*}{ p-value } \\
\hline & Mean & SD & Mean & SD & \\
\hline IVRT & 54.8 & 12.2 & 56.8 & 3.8 & 0.408 \\
\hline IVCT & 43.1 & 6.1 & 37.3 & 2.6 & $<0.0001$ \\
\hline ET & 270.4 & 15.3 & 274.8 & 6.1 & 0.151 \\
\hline $\mathbf{E}$ & 0.8 & 0.2 & 0.9 & 0.2 & 0.121 \\
\hline $\mathbf{A}$ & 0.4 & 0.1 & 0.4 & 0.1 & 0.700 \\
\hline $\mathbf{E} \backslash \mathbf{A}$ & 1.8 & 0.3 & 1.8 & 0.4 & 0.991 \\
\hline MPI RV & 0.37 & 0.04 & 0.34 & 0.02 & 0.006 \\
\hline Variable & No & $\%$ & No & $\%$ & p-value \\
\hline \multicolumn{6}{|l|}{ MPI RV } \\
\hline High & 9 & $30.0 \%$ & 0 & $0.0 \%$ & \multirow{2}{*}{0.002} \\
\hline Normal & 21 & $70.0 \%$ & 30 & $100.0 \%$ & \\
\hline
\end{tabular}

IVRT: isovolumic relaxation time; IVCT: isovolumic contraction time; ET: ejection time; A:A wave; E: E wave; MPI RV: right ventricular myocardial performance index.

Table (4): Comparison between patients and controls as regards Tissue Doppler of the left ventricle 
ISSN: 2536-9482 (Online) Fayoum University Medical Journal Kamel et al., 2020,6(1), 18-27

\begin{tabular}{|c|c|c|c|c|c|}
\hline \multirow[t]{2}{*}{ Variable } & \multicolumn{2}{|c|}{$\begin{array}{c}\begin{array}{c}\text { PNS patients } \\
(\mathrm{n}=30)\end{array} \\
\end{array}$} & \multicolumn{2}{|c|}{$\begin{array}{c}\begin{array}{c}\text { Controls } \\
(\mathrm{n}=30)\end{array} \\
\end{array}$} & \multirow[t]{2}{*}{ p-value } \\
\hline & Mean & SD & Mean & SD & \\
\hline IVRT & 57.9 & 6.5 & 53.9 & 3.8 & 0.005 \\
\hline IVCT & 43.1 & 8.4 & 50.3 & 15.7 & 0.032 \\
\hline ET & 275.4 & 11.4 & 278.9 & 4 & 0.111 \\
\hline $\mathbf{E}$ & 0.9 & 0.2 & 1 & 0.2 & 0.003 \\
\hline $\mathbf{A}$ & 0.5 & 0.1 & 0.6 & 0.1 & 0.003 \\
\hline $\mathbf{E} \backslash \mathbf{A}$ & 1.8 & 0.2 & 1.8 & 0.2 & 0.901 \\
\hline MPI LV & 0.37 & 0.04 & 0.35 & 0.01 & 0.009 \\
\hline Variable & No & $\%$ & No & $\%$ & p-value \\
\hline \multicolumn{6}{|l|}{ MPI LV } \\
\hline High & 6 & $20 \%$ & 0 & $0.0 \%$ & \multirow{2}{*}{0.024} \\
\hline Normal & 24 & $80 \%$ & 30 & $100.0 \%$ & \\
\hline
\end{tabular}

IVRT: isovolumic relaxation time; IVCT: isovolumic contraction time; ET: ejection time; A: A wave; E: E wave; MPILV: left ventricular myocardial performance index.

Table (5): Comparison between patients with high and normal right ventricle MPI as regards disease characteristics

\begin{tabular}{|c|c|c|c|c|c|}
\hline \multirow[t]{2}{*}{ Variable } & \multicolumn{2}{|c|}{$\begin{array}{l}\text { High } \\
(\mathrm{N}=9)\end{array}$} & \multicolumn{2}{|c|}{$\begin{array}{c}\text { Normal } \\
(\mathrm{N}=21)\end{array}$} & \multirow[t]{2}{*}{ p-value } \\
\hline & Mean & SD & Mean & SD & \\
\hline Disease duration (months) & 26.4 & 8.8 & 11.9 & 13.8 & 0.007 \\
\hline $\begin{array}{l}\text { Treatment duration } \\
\text { (months) }\end{array}$ & 22.4 & 5.3 & 11.8 & 13.8 & 0.034 \\
\hline Variable & $\mathbf{N}$ & $\%$ & $\mathbf{N}$ & $\%$ & p-value \\
\hline \multicolumn{6}{|l|}{ Attack } \\
\hline Relapse & 9 & 100.0 & 5 & 23.8 & \multirow{2}{*}{$<0.0001$} \\
\hline First attack & 0 & 0.0 & 16 & 76.2 & \\
\hline \multicolumn{6}{|l|}{ Steroid sensitivity } \\
\hline Sensitive & 7 & 77.8 & 21 & 100.0 & \multirow{2}{*}{0.025} \\
\hline Resistance & 2 & 22.2 & 0 & 0.0 & \\
\hline \multicolumn{6}{|l|}{ Immuno-suppressive } \\
\hline Yes & 2 & 22.2 & 0 & 0.0 & \multirow{2}{*}{0.025} \\
\hline No & 7 & 77.8 & 21 & 100.0 & \\
\hline
\end{tabular}


Table (6): Comparison between patients with high and normal left ventricle MPI as regards disease characteristics

\begin{tabular}{|c|c|c|c|c|c|}
\hline \multirow[t]{2}{*}{ Variable } & \multicolumn{2}{|c|}{$\begin{array}{l}\text { High } \\
(\mathrm{N}=6)\end{array}$} & \multicolumn{2}{|c|}{$\begin{array}{c}\text { Normal } \\
(\mathrm{N}=\mathbf{2 4})\end{array}$} & \multirow[t]{2}{*}{ p-value } \\
\hline & Mean & SD & Mean & SD & \\
\hline Disease duration (months) & 25.7 & 9.4 & 13.9 & 14.2 & 0.031 \\
\hline $\begin{array}{l}\text { Treatment duration } \\
\text { (months) }\end{array}$ & 21.7 & 5.3 & 13.3 & 13.7 & 0.026 \\
\hline Variable & $\mathbf{N}$ & $\%$ & $\mathbf{N}$ & $\%$ & p-value \\
\hline \multicolumn{6}{|l|}{ Attack } \\
\hline Relapse & 6 & 100 & 8 & 33.3 & \multirow{2}{*}{$<0.0001$} \\
\hline First attack & 0 & 0 & 16 & 66.7 & \\
\hline \multicolumn{6}{|l|}{ Steroid sensitivity } \\
\hline Sensitive & 4 & 66.7 & 24 & 100 & \multirow{2}{*}{0.003} \\
\hline Resistance & 2 & 33.3 & 0 & 0.0 & \\
\hline \multicolumn{6}{|l|}{ Immuno-suppressive } \\
\hline Yes & 2 & 33.3 & 0 & 0 & \multirow{2}{*}{0.003} \\
\hline No & 4 & 66.7 & 24 & 100 & \\
\hline
\end{tabular}

Mean \pm SD

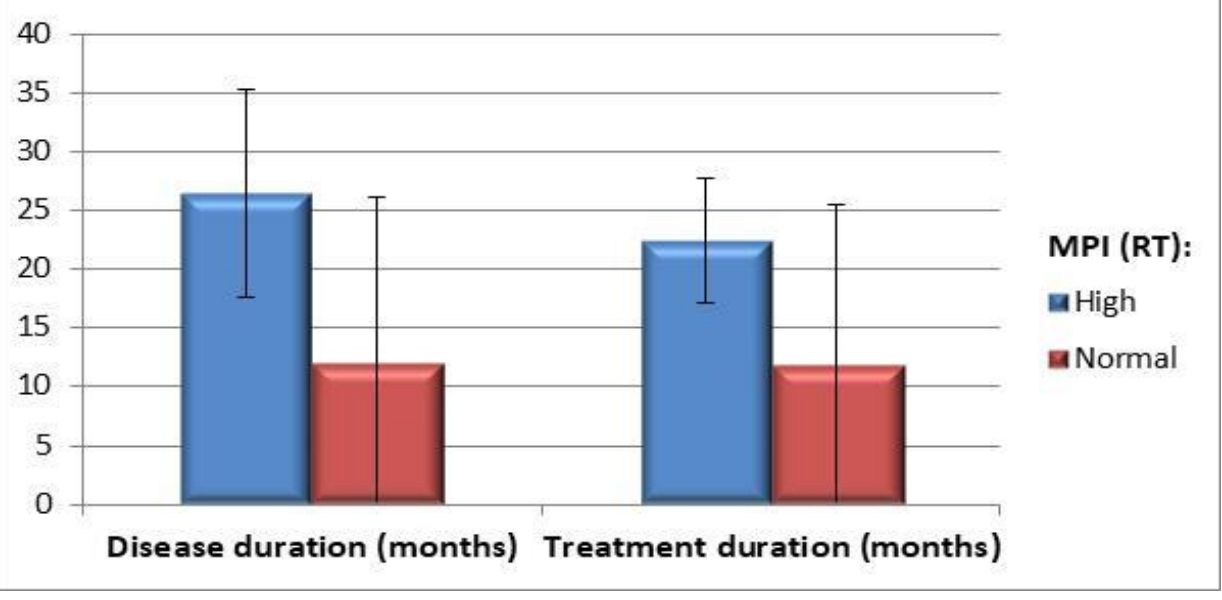

Figure (1): Comparison between patients with normal and high right ventricle MPI as regards disease and treatment duration. 
ISSN: 2536-9482 (Online) Fayoum University Medical Journal Kamel et al., 2020,6(1), 18-27

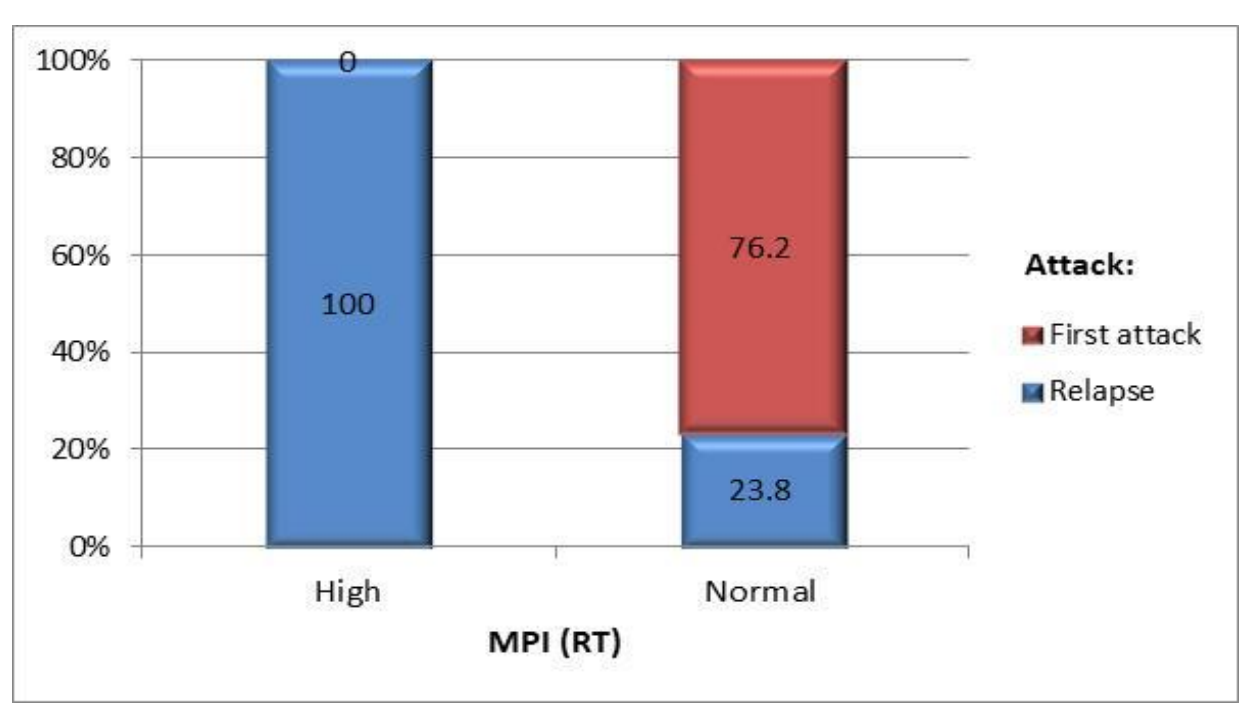

Figure (2): Comparison between patients with normal and high right ventricle MPI as regards disease attack

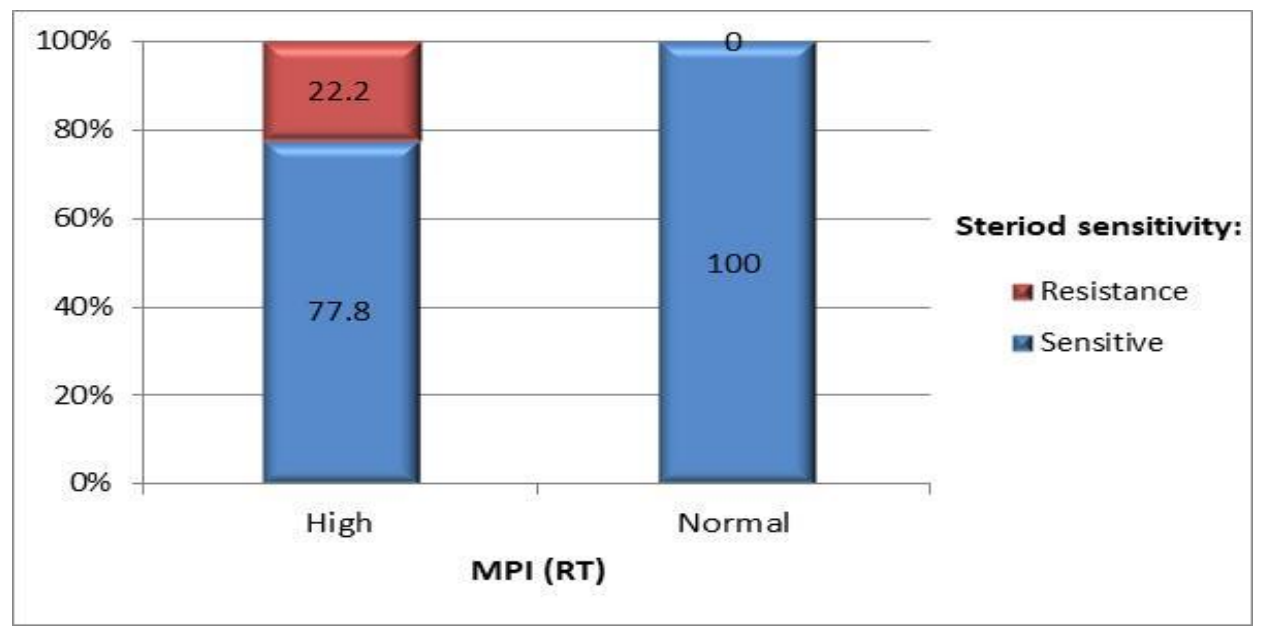

Figure (3): Comparison between patients with normal and high right ventricle MPI as regards steroid sensitivity

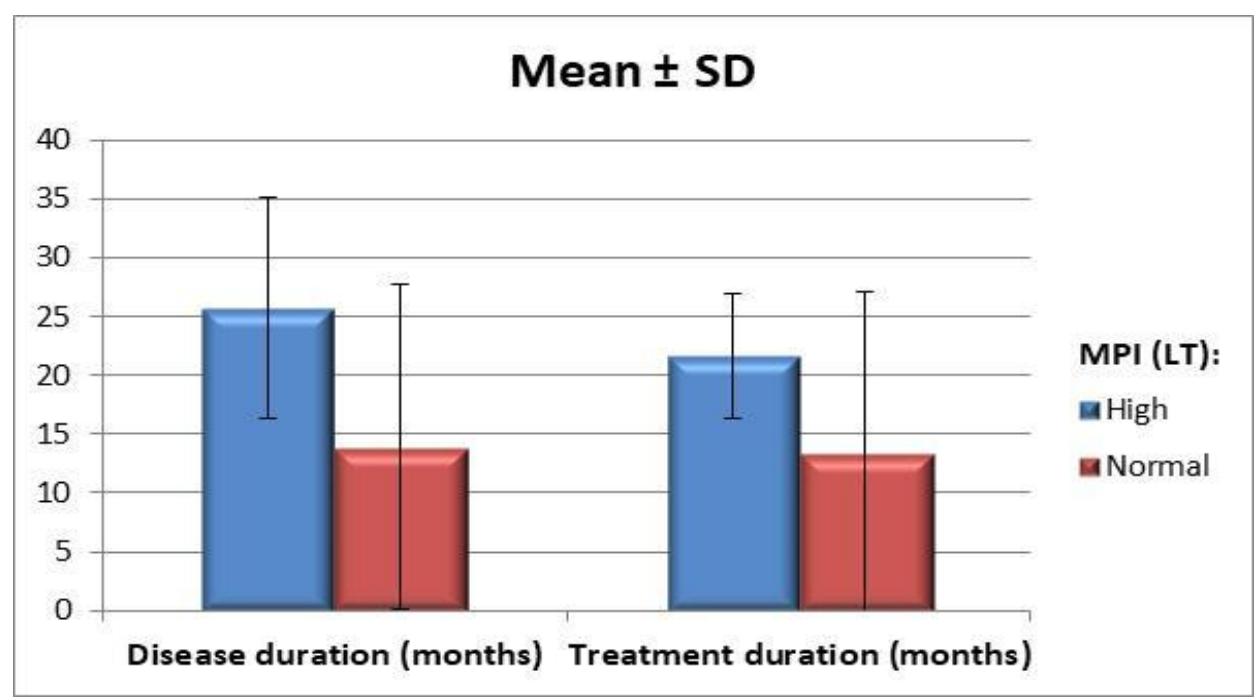


Figure (4): Comparison between patients with normal and high left ventricle MPI as regards disease and treatment duration.

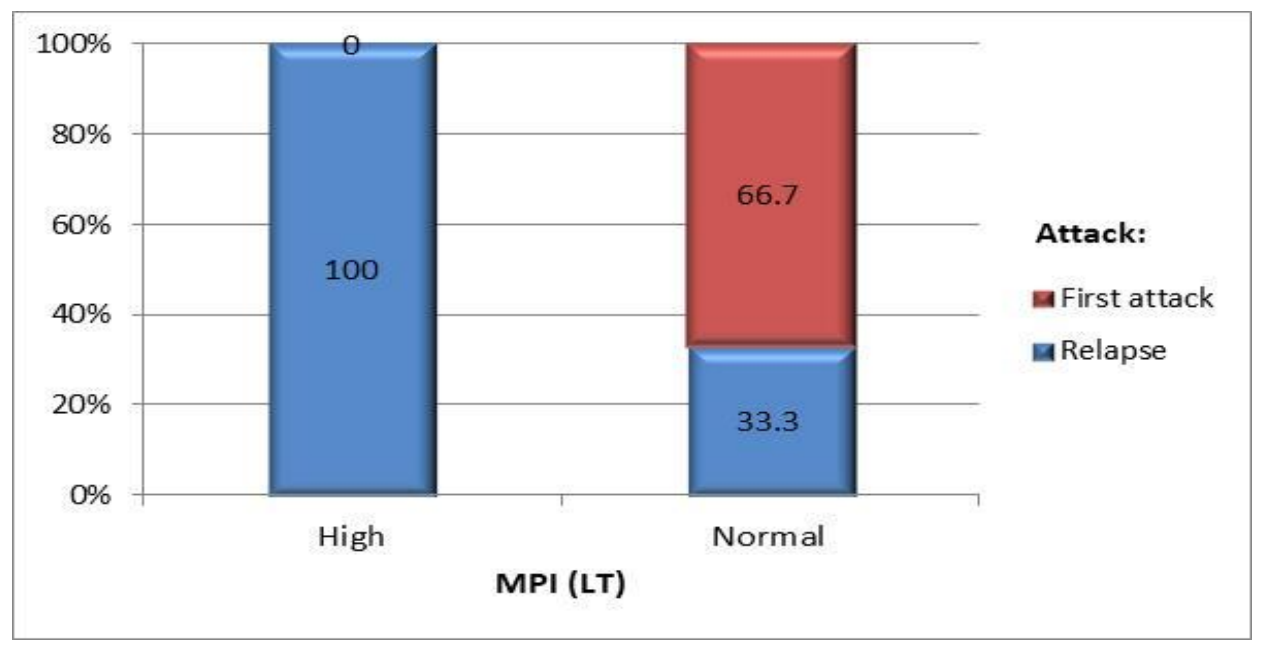

Figure (5): Comparison between patients with normal and high left ventricle MPI as regards disease attack.

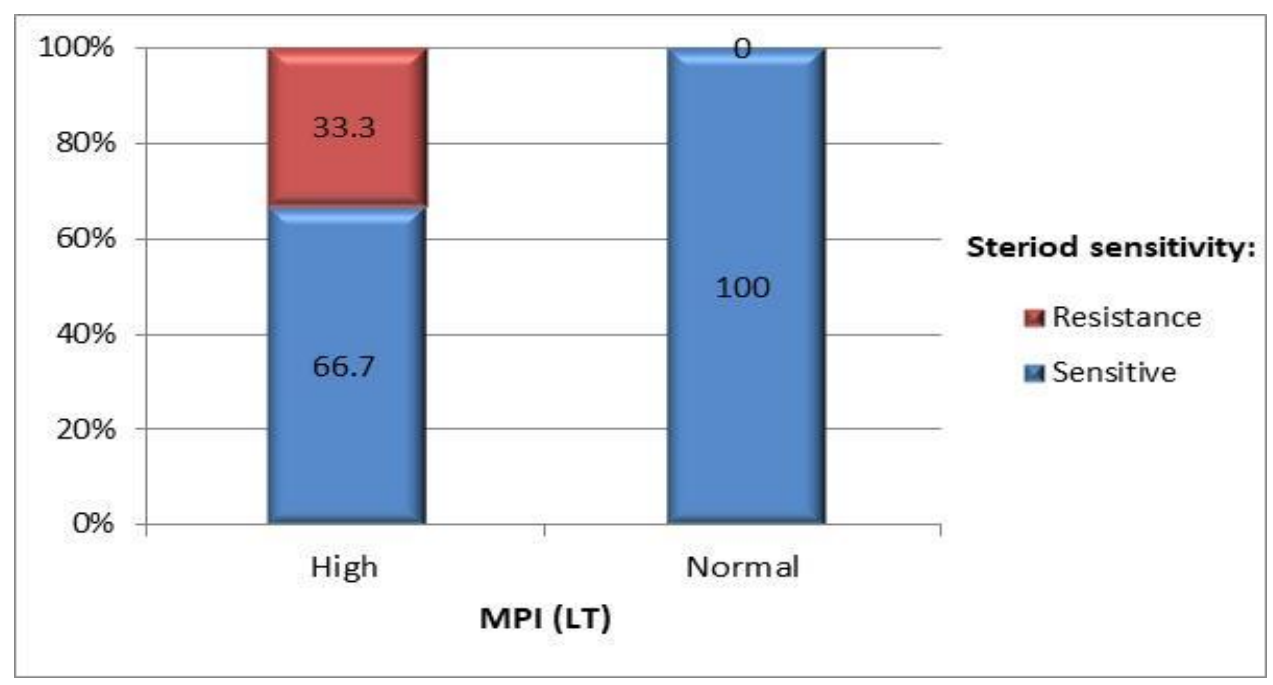

Figure (6): Comparison between cases with normal and high left ventricle MPI as regards steroid sensitivity

\section{Discussion}

Primary nephrotic syndrome (PNS) is the most common chronic renal disease of childhood. ${ }^{(8)}$ Malnutrition and inflammation associated with nephrotic syndrome can lead to an increase in cardiovascular events $^{(\mathbf{4})}$. The aim of this study was to assess cardiac performance in children with nephrotic syndrome using echocardiography and tissue Doppler.

In this study, with the exception of LVESD, there was no significant difference between patient group and control group as regards structural changes in the heart, evaluated by conventional echocardiography. Another study by Abd Elaziz et al., $2019^{(9)}$ showed that there was no significant difference between patient and control group as regard conventional echocardiographic parameters. However, Du et al., (10) in their study in 2004 showed that pulmonary arterial pressure (PAP) was increased in children with nephrotic syndrome.

As regards right ventricle tissue Doppler echocardiography, results of this study showed that isovolumic contraction time (IVCT) was 
significantly higher in the patient group compared to the control group $(\mathrm{p}<0.0001)$. Similar results were reported by Saleh et al., $2018^{(11)}$ who reported that IVCT was increased in cases $(\mathrm{p}=0.02)$.

As regards right ventricle MPI, there was statistically significant increase in MPI values in $30 \%$ of patient group compared to $0 \%$ in control group ( $\mathrm{p}=0.002)$ in this study. Similar results were reported by Saleh et al., $2018^{(11)}$. In contrast, Abd Elaziz et al., 2019(9) showed that there was no significant difference between patient and control group as regards Tie index.

As regards left ventricle tissue Doppler echocardiography, there was significant difference between patients and control groups as regards left ventricle IVRT and IVCT. Left ventricle MPI was increased in $20 \%$ of nephrotic cases compared to $0 \%$ in control group ( $\mathrm{p}=0.024)$. Saleh et al., $2018^{(\mathbf{1 1})}$ also reported significance difference between patients and control as regards left ventricle IVRT ( $\mathrm{p}=$ $0.001)$, IVCT $(\mathrm{p}=0.006)$, and E/A Ratio $(\mathrm{p}=0.002)$.

In this study, there was an association between high MPI RV (right ventricle diastolic dysfunction) and disease duration $(\mathrm{p}=0.007)$, This agrees with a study done by Qin et al. in $2010^{(3)}$ who demonstrated that patients with increased right ventricle (RV) dysfunction had a longer duration since disease onset $(p=0.015)$.

This study showed that there was association between steroid resistance and high MPI RV ( $\mathrm{p}=$ $0.025)$ and high MPI LV ( $\mathrm{p}=0.003)$, this could be due to long term steroid \pm cytotoxic therapy, and also due to increased susceptibility of development of chronic renal failure. While in Qin et al., in $2010^{(3)}$ study, there was no difference in terms of steroid dependence or steroid resistance.

In conclusion, RV functions were affected (high RV MPI) in $30 \%$ of children with PNS and LV functions (high LV MPI) were affected in $20 \%$ of cases. LV and RV dysfunction (high MPI) were significantly associated with disease duration, treatment duration, relapse, steroid resistance and with immune- suppressive drugs. Follow up tissue Doppler echocardiography of nephrotic syndrome patients especially with long disease duration and on immunosuppressive drugs is recommended.

\section{References}

1. Eddy AA, Symons JM. Nephrotic syndrome in childhood. Lancet 2003; 362(9384): 62939.

2. Kerlin BA, Haworth K, Smoyer WE. Venous thromboembolism in pediatric nephrotic syndrome. Pediatr. Nephrol. 2014; 29(6):989-997.

3. Qin, Q, Xu R, Dong J, et al. Corrigendum to "evaluation of right ventricle function in children with primary nephrotic syndrome" Pediatr. Neonatol. 2010; 51 :166-171.

4. Nakamura A, Niimi R, Kurosaki K, and Yanagawa $Y$. Factors influencing cardiovascular risk following termination of glucocorticoid therapy for nephrotic syndrome. Clin. Exp. Nephrol. 2010; 14(5), 457-462.

5. Correia Pinto J, Henriques-Coelho T, Roncon-Albuquerque Jr R, et al. Differential right and left ventricular diastolic tolerance to acute afterload and NCX gene expression in Wistar rats. Physiol. Res. 2006;55:513-526.

6. Lilova MI, Velkovski IG, Topalov IB. Thromboembolic complications in children with nephrotic syndrome in Bulgaria. Pediatr. Nephrol. 2000; 15:74-78.

7. Hooman N, Isa-Tafreshi R, Otukesh H, et al. Carotid artery function in children with idiopathic nephrotic syndrome. Nefrologia: publicacion oficial de la Sociedad Espanola Nefrologia. 2013; 33(5):650-656

8. Schachter AD. The pediatric nephrotic syndrome spectrum: clinical homogeneity and molecular heterogeneity. Pediatr. Transplant. 2004; 8(4):344-348.

9. Abd Elaziz LR, Abouzeid HM, Abu Fares KY. Myocardial Dysfunction in Children 
with Nephrotic Syndrome, A Tissue Doppler Study Zagazig University Medical Journal 2019; 25(3): 409-418.

10. Du ZD, Cao L, Liang L, et al. Increased pulmonary arterial pressure in children with nephrotic syndrome. Arch. Dis. Child. 2004 Sep; 89 (9): 866-870.

11. Saleh SM, Elmaghraby MKS, Abdelfadil $\mathrm{AM}$ et al. Myocardial Performance Index in Nephrotic Syndrome. J. Clin. Exp. Cardiolog. 2018; 9(4): 585. 